\title{
Saúde é colocar-se em risco: normatividade vital em Georges Canguilhem
}

\section{Health is putting oneself at risk: vital normativity in Georges Canguilhem}

\author{
Tiago Iwasawa Neves \\ Universidade Federal de Campina Grande. Campina Grande, \\ PB, Brasil. \\ E-mail: tiagoiwasawa®yahoo.com.br \\ Luiza Almeida Porcaro \\ Universidade Estadual da Paraíba. Campina Grande, PB, Brasil. \\ E-mail: luizaporcaroœhotmail.com

\section{Daniel Rangel Curvo} \\ Universidade Estadual da Paraíba. Campina Grande, PB, Brasil. \\ E-mail: danielcurvoळhotmail.com
}

\section{Correspondência}

Tiago Iwasawa Neves

Av. Juvêncio Arruda, 795. Campina Grande, PB, Brasil. CEP 58429-140.

\section{Resumo}

Este artigo objetiva apresentar uma crítica ao modelo biomédico de saúde predominante nas ciências médicas, a partir do conceito de normatividade vital, proposto por Georges Canguilhem. Na introdução apresentamos, a partir de um breve histórico do conceito de saúde, a normalização como o primado fundamental do modelo biomédico. Na primeira parte, discutimos o problema da determinação do normal e do patológico, da saúde e da doença, no pensamento de Canguilhem, buscando situar esses conceitos em função de valores individuais, questionando a existência de um processo normativo em biologia. $\mathrm{Na}$ segunda parte, pretende-se demonstrar que a normatividade vital defendida por Canguilhem é uma ferramenta conceitual fundamental para o entendimento da lógica de produção biológica. Esta lógica de produção não toma a norma como critério de valoração das formas de vida possíveis. Não são as individualidades biológicas que se adéquam ou se afastam das normas, mas, ao contrário, é a individualidade biológica enquanto potência de criação de novas formas que produz o processo de sua normatividade. Por fim, destacamos o impacto crítico do conceito de saúde entendido como uma abertura ao risco, enfatizando essa dimensão da saúde como a capacidade de enfrentar novas situações de vida. Palavras-chave: Saúde; Risco; Normatividade Vital; Georges Canguilhem. 


\section{Abstract}

This article aims to criticize the biomedical health model prevalent in medical sciences, based on the concept of vital normativity proposed by Georges Canguilhem. In the introduction we present, from a brief history of the health concept, normalization as the fundamental primacy of the biomedical model. In the first part, we discuss the problem of determining normal and pathological, health and illness in Canguilhem's thought, seeking to situate these concepts in function of individual values, questioning the existence of a normative process in Biology. In the second part, it aims to demonstrate that the vital normativity advocated by Canguilhem is a fundamental conceptual tool for the understanding of organic production logic. This production logic in Biology does not take the norm as criterion for valuing possible forms of life. Biological individuals do not fit or deviate from the rules, but biological individuality, as a power of generating new ways, produces the normativity process. Finally, we highlight the critical impact of the concept of health understood as an openness to risk, emphasizing this dimension of health as capacity to face new situations of life.

Keywords: Health; Risk; Vital Normativity; Georges Canguilhem.

\section{Introdução}

A noção de saúde é definida a partir de contextos e concepções determinadas, ou seja, varia conforme determinações histórico-sociais e desencadeia uma racionalidade clínica e uma política de cuidado diferentes. Segundo Scliar (2007), durante a antiguidade, em diferentes culturas, as doenças foram consideradas como resultado de uma possessão por algum ser maligno ou como uma punição por um desvio moral ou impureza do espírito infligida por uma força sobrenatural. A medicina mágico-religiosa, segundo Volich (200o), definia o adoecer como uma experiência que resulta da manifestação de forças alheias no organismo, induzidas por força do pecado ou da maldição. Dessa forma, a cura estava na crença de que os curandeiros e os xamãs - intermediários entre os homens e as entidades divinas - pudessem anular as forças do mal através da magia e de rituais religiosos. Para os antigos hebreus, as doenças não eram necessariamente produtos de uma possessão por forças sobrenaturais, mas representavam sempre a cólera divina diante dos fracassos e erros humanos. Alguns autores (Scliar, 2007; Volich, 2000) lembram como, no Antigo Testamento, antes de ser reconhecida como uma doença que poderia implicar um modo de tratamento, a lepra era definida como resultado da desobediência ao mandamento divino.

Ainda de acordo com o autor, foi com a medicina grega que a história do conceito de saúde distanciou-se das explicações puramente mágico-religiosas. Hipócrates (46o-377 a.C.), conhecido como o pai da Medicina, "sustentava que as enfermidades não eram causadas por deuses ou demônios, mas que resultavam de fatores naturais ligados ao modo de vida. As pessoas adoeciam por causa do trabalho que exerciam, do local onde moravam, do alimento ou da água que ingeriam" (Dantas, 2014, p. 116). Ainda segundo a autora, poderíamos pensar uma continuidade entre o homem, a sua natureza e o meio ambiente que o cerca, fazendo com que a saúde fosse pensada como a expressão do exercício cotidiano da sua existência.

Com o desenvolvimento do pensamento mecanicista, apresentado principalmente por René Descartes (1596-1650), o corpo passou a ser analisado tal como uma complexa máquina, dividida em 
elementos cada vez mais simples para se permitir um melhor entendimento. Essa perspectiva gerou um importante desenvolvimento das explicações e práticas de cuidado, constituindo as bases do da clínica e do método científico moderno (Ribeiro, 2007).

A origem e as razões para o sofrimento humano passam a ser atribuídas cada vez mais às alterações neurofisiológicas e/ou genéticas, e os avanços tecnológicos da medicina implicam cada vez mais em um discurso medicamentoso. É importante lembrar que por "discurso medicamentoso" não dizemos apenas de modelos de tratamento que localizam a causa da doença em um marcador biológico determinado, fazendo assim do fármaco o único agente da cura, mas também é um modo de enfrentar toda e qualquer doença como não só passível de cura, mas necessariamente curável. A vida narcotiza-se e a indústria farmacêutica passa a apresentar o uso de medicamentos como uma "concreta possibilidade de obtenção de saúde e para muitos outros como a concreta felicidade" (Dantas, 2014, p. 119).

Este novo modo de se relacionar com a saúde torna-se, acima de tudo, uma relação mercadológica, há uma promessa implícita de que consumir produtos saudáveis e remédios irá adequá-lo a um padrão estético e social considerado ideal por essa sociedade capitalista contemporânea em que vivemos.

O modelo biomédico assume assim um caráter de regulador moral, "produtor de crenças, valores, desejos e padrões coletivos” (Dantas, 2014, p. 120). Eis aqui o que pretendemos destacar com este texto: o modelo biomédico de saúde não é apenas um paradigma de gestão de um domínio importante em nossa vida, mas, antes, é uma racionalidade que procura determinar as possibilidades de se viver uma vida. Saúde, então, não diz mais respeito apenas à ausência de doenças, mas também a consumir determinados produtos, medicamentos - melhor dizendo, consumir um determinado modelo de vida. Segundo Birman (2001, p. 185), este atual modelo de saúde "não pretende mais a cura, no sentido clássico da medicina clínica, mas apenas a regulação do mal-estar".

Lembremos ainda que o surgimento desse modelo é tributário do nascimento da clínica moderna, pois, segundo Michel Foucault (2008), mais do que um evento histórico que marca o surgimento de um dispositivo de poder sobre os corpos, o nascimento da clínica, acima de tudo, significa pensar, a partir de então, que o conceito de saúde/doença, longe de estar no terreno objetivo da patologia médica, se coloca no eixo incerto da "gramática da doença", ou seja, sob esse modo nada objetivo com que o saber transforma a doença em discurso pronto para ser lido e interpretado pelo olhar clínico. A partir disso, a doença e a saúde não têm uma gramática própria, pois a maneira com que elas falam depende da maneira com que organizamos o que há a ser visto e ouvido.

Por outro lado, devemos também reter que o desenvolvimento moderno do setor saúde consolidou-se em um importante dispositivo de controle das populações e dos indivíduos, apresentando socialmente normas e parâmetros existenciais considerados aceitos, valorizados e normais. A sustentação dessas normas e parâmetros advém exatamente do que escapa à regra, à norma. É com a produção dos fenômenos anormais que o normal e a norma justificam-se e impõem-se (Canguilhem, 2009). Assim, não é difícil explicar por que a aplicação do modelo biomédico de saúde ampliou-se com a necessidade de prevenção de doenças e controle dos riscos, pois, com o intenso crescimento das cidades pós-Revolução Industrial, se alastraram doenças por contaminação, como a gripe, o sarampo, a tuberculose, a cólera e a febre amarela. Contudo, esse modelo de saúde não foi efetivo apenas na prevenção de doenças contagiosas, mas também no combate de doenças instaladas e infecções.

O processo de determinação positiva da saúde e da doença foi analisado e descrito por Canguilhem (2009) e chamado de processo de normalização. Entendendo o setor saúde como uma das grandes forças disciplinalizadoras da modernidade, buscamos apresentar uma crítica ao paradigma biomédico dominante no campo da ciência médica. Esse paradigma será colocado em questão a partir do conceito de normatividade vital, proposto por Georges Canguilhem.

Para apresentar essas ideias, optamos por dividir o texto em três partes: a primeira, "Norma e normalização: a determinação da doença e da saúde”, trata da delimitação do que seria o normal, o patológico, a saúde e a doença, buscando percebê-los como valores individuais e como caminhos para o questionamento da normatividade biológica. 
A segunda parte, "Normatividade vital: uma outra perspectiva em saúde”, propõe-se a discutir o conceito de normatividade vital em Georges Canguilhem para, posteriormente, esboçar uma lógica de produção biológica que não toma a norma como critério de valoração das formas de vida possíveis. E, por fim, nas "Considerações Finais", destacamos o impacto crítico do conceito de saúde entendido como uma abertura ao risco, enfatizando essa dimensão da saúde como a capacidade de enfrentar as situações novas que interferem na vida de um sujeito.

\section{Norma e normalização: a determinação da doença e da saúde}

Para entendermos melhor esta lógica de produção dos fenômenos anormais, é altamente ilustrativo evocarmos o conto "O alienista", de Machado de Assis (Costa, 2007)1. Ora, segundo Christian Dunker (2015), a racionalidade diagnóstica, que contamina o espírito de Simão Bacamarte, é a seguinte: a inclusão da singularidade (o modo de cada um ser louco) na cláusula genérica da anormalidade (loucura é a perda do perfeito equilíbrio das faculdades). No entanto, se tudo é a loucura, como bem suspeitam os cidadãos de Itaguaí, nada então, nenhum critério objetivo e científico, serve para a definição de sua verdade e de seus efeitos normativos. Se há uma extensão da regra na tentativa de eliminar aquilo que ela não pode determinar ou predicar, então o paradoxo é que a regra não pode representar mais nada. Conclusão que se antecipa: a norma não pode ser o regime exclusivo de determinação das formas de vida possíveis.

Eis o drama que nos afeta, no conto, quando a teoria que sustenta a ação terapêutica do alienista se "inverte". Conhecemos bem a cena: diante da enorme incidência diagnóstica - cerca de $80 \%$ da população de Itaguaí já estava recolhida na Casa
Verde - a loucura é assumida enquanto outra realidade: não é mais a quebra do perfeito equilíbrio das faculdades, mas sim o seu oposto, ou seja, é estar com o juízo perfeitamente equilibrado. Ao alterar a perspectiva, assistimos à renovação dos habitantes da Casa Verde e, com isso, o modo de tratá-los é transformado até a obtenção da cura pelo retorno ao estado normal, o que, no caso, passou a ser a qualidade de não estar no perfeito equilíbrio das faculdades mentais.

Apesar dessa mudança de perspectiva, não observamos, contudo, uma inversão tão radical no modo de tratar o problema. 0 que permanece enquanto continuidade do espírito é a marca do regime de normalização: a definição dos fenômenos patológicos pela determinação - normas estáveis, valores imutáveis e constantes - dos processos normais. Não é difícil constatar que o que se modifica é apenas a atribuição da loucura e não a condição da loucura enquanto exceção à norma, ou seja, identificada enquanto diferença em relação à norma. 0 que faltou a Bacamarte foi entender que a loucura não é a exceção da razão, mas sim uma experiência que não se pode medir pela norma, indeterminada a priori, sem predicação e atributos inerentes que a façam ser reconhecida pelo saber e pelo regime normativo em vigor. Por isso, a loucura pode ser pensada como um tipo de experiência com alto potencial de transformação adaptativa ao meio. Faltou ao alienista, assim, considerar a loucura como potência de criação de uma nova norma subjetiva, de um modo de viver que não pode ser avaliado na dimensão do fato, mas somente na do valor. Tal como atesta Fábio Franco,

Com efeito, se a ciência é conhecimento dos fatos, e se a ela cabe orientar a técnica na cura das patologias vitais e sociais, é porque esses fatos exprimem pela sua frequência ou generalidade o único ideal normativo ao qual se deve adequar os

\footnotetext{
1 Um bem-sucedido médico, Simão Bacamarte, retorna a sua cidade natal, Itaguaí, em uma tentativa de dedicar-se mais profundamente à Medicina, principalmente à Psiquiatria, decidindo-se por construir um manicômio, o Casa Verde, para abrigar todos os loucos da cidade e seu entorno. Porém, com o passar do tempo, Dr. Bacamarte passa a identificar tantos sujeitos como loucos que não há mais vagas em seu manicômio. Nesse momento, toda exceção, todo comportamento desviado de um normal é visto como loucura e deve ser contido. Posteriormente, duas revoltas populares que objetivavam acabar com o excesso de internações acentua-as, levando ao ponto de cerca de $80 \%$ da população de Itaguaí estar internada no Casa Verde. Nesse momento, Dr. Bacamarte percebe que sua teoria estava equivocada e resolve libertar todos os loucos de seu manicômio, e internar outros, os ditos, até então, normais. Após perceber que estava novamente equivocado, Dr. Bacamarte conclui ser ele o único anormal e interna-se no Casa Verde pelo resto de sua vida.
} 
fenômenos desviantes. Nesse sentido, a cura só pode significar recuperação ou restabelecimento de um certo valor normal definido em termos quantitativos (Franco, 2012, p. 51).

Faltou ao personagem machadiano, finalmente, perceber que a norma não é um atributo ou um regime que fixa e predetermina as possibilidades de existência das formas de vida. É preciso neste momento insistir que a indeterminação não é o valor assimétrico de determinação. “A indeterminação possui estatuto ontológico próprio, mesmo que negativo, e não deve ser concebida apenas como negação, suspensão ou transgressão da lei (automaton), mas também como contingência e encontro (tichê)" (Dunker, 2011, p. 123).

Procurando demonstrar que a experiência de indeterminação tomada como contingência transformadora (tichê) é o estatuto ontológico das chamadas “ciências da vida", o filósofo Vladimir Safatle (2015; 2011) propõe que o conceito de normatividade na obra de Georges Canguilhem nos permite pensar em um tipo diferente de dinamismo vital que leva em consideração o poder político transformador das experiências produtivas de indeterminação.

A vida, na visão de Canguilhem, é definida enquanto uma atividade normativa que vai contra tudo o que indica um valor negativo. Ser normativo, na qualidade de vivente, significa a potência de produzir outras formas de ajustamento e, por essa razão, significa também a recusa da fixidez e da naturalização enquanto fundamentos da adaptabilidade ao meio. Isso nos remete a ideia de que estar doente, curar-se e recuperar a saúde não é um processo que se normaliza e fixa de uma vez por todas os seus critérios de reconhecimento.

Segundo Canguilhem (2009), o estudo da ciência da vida implica em uma substituição do regime de normalização pelo regime da normatividade: se há um princípio que rege a vida e a produção de suas formas, este é um princípio, por definição, dinâmico, contingente e indeterminado, ou seja, produtor de novas normas de ajustamento do vivente ao meio. Nesse sentido, o conceito de normatividade em Canguilhem nos ajuda a colocar em questão a existência de uma clara fronteira de distinção do normal e do patológico, porque,
Quando classificamos como patológico um sistema ou um mecanismo funcional isolado, esquecemos que aquilo que os torna patológicos é a relação de inserção na totalidade indivisível de um comportamento individual. Há uma diferença qualitativa fundamental que atinge todo o organismo com a integralidade de seus processos e funções. Pois não haveria um único fenômeno que se realizaria no organismo doente da mesma forma que no organismo são. Canguilhem chega mesmo a afirmar que ser doente é, para o homem, viver uma vida diferente. Notemos ainda que tal estratégia de vincular o normal a partir de uma relação normativa de ajustamento ao meio implica afirmar que não há fato algum que seja normal ou patológico em si. Eles são normal e patológico no interior de uma relação entre organismo e meio ambiente (Safatle, 2011, p. 18).

Ora, se há uma distinção entre o normal e o patológico esta não é uma diferença fixa e estática entre a norma e o seu desvio. Poderíamos dizer que o normal, assim como o patológico, não são experiências idênticas para sujeitos diferentes. Eis uma questão central que toda teoria da saúde e qualquer abordagem clínica não podem deixar de enfrentar. A tese de que o normal serve de protótipo para as formas patológicas define, ainda hoje, o pensamento e o ato médico, o que provoca uma reflexão reducionista para a cura, já que o objetivo terapêutico, a partir dessa racionalidade, só pode ser a reparação e a restauração do estado normal. Percebemos que em Georges Canguilhem se pode encontrar saídas para o impasse da "razão normativa", pois, segundo Safatle (2015), ao focar a distinção entre o normal e o patológico, ele é levado a propor um dinamismo concreto para se pensar a atividade vital. A vida possui uma característica fundamental: ela é, antes de tudo, uma atividade polarizada contra tudo que é da ordem da inércia e da indiferença. Isso significa que é próprio à vida ser uma atividade normativa de produção, não só de novas formas de vida, mas também de novos ajustamentos do organismo em relação ao meio, o que a coloca sempre contra os "valores negativos" da doença e do risco de morte, por exemplo. Por esta razão, é difícil pensar que a distinção entre o normal e o patológico possa ser fruto de uma ciência exata. 0 fato de não existir ciências do normal e do patológico 
significa, antes de tudo, afirmar que a distinção entre eles não está no domínio do fato, mas no campo de problemas do valor.

Seria conveniente dizer que o fato patológico como signo de alteração do estado normal só pode ser definido e apreendido no nível de uma totalidade orgânica. No caso do homem, no nível da consciência de que a experiência da doença possui valor negativo. Assim, nenhuma doença é, em sentido estrito, de um órgão ou função específicas, mas, antes, doença do organismo cujo modo de funcionamento está transformado. Estar doente é, do ponto de vista biológico, viver uma outra vida, uma condição nova que exige do indivíduo a capacidade de produzir novas formas de ajustamento com o meio, isto é, novas formas de vida. Para Canguilhem, a fisiologia só sabe que está diante de fatos patológicos na medida em que a clínica fornece a ela importantes indicações,

Pois a clínica coloca o médico em contato com indivíduos completos e concretos, e não com seus órgãos e funções. A patologia, quer seja anatômica ou fisiológica, analisa para melhor conhecer, mas ela só pode saber que é uma patologia - isto é, estudo do mecanismo da doença - porque recebe da clínica essa noção de doença, cuja origem deve ser buscada na experiência que os homens têm de suas relações de conjunto com o meio (Canguilhem, 2009, p.54-55).

Se estas proposições têm algum sentido, se pergunta com propriedade Canguilhem, por que o clínico contemporâneo adota com mais frequência o ponto de vista da fisiologia e não o da clínica? Talvez, prossegue o autor, seja porque o profissional médico desconhece que a doença para o doente é uma forma diferente de vida e não apenas modificações funcionais tomadas isoladamente. As doenças são, literalmente, novos modos de vida. Poderíamos dizer ainda que, se a fisiologia pode ser considerada a ciência das funções e dos modos de vida, é porque o dinamismo vital oferece a ela infinitos modos, cujas leis lhe cabe codificar. Caso não existissem as doenças, seus modos inesperados e imprevisíveis de afetação subjetiva, a fisiologia seria a representação reiterada de uma única e mesma lei.

Só assim é possível concluir que os termos normal e patológico não possuem sentido absoluto ou valor essencial. Nenhum vivente, nenhum meio, enfim, nenhum homem pode ser considerado normal ou anormal isoladamente. Cada individualidade é uma figura da invenção biológica, exemplo vivo de um tipo de dinamismo vital que não é a produção reiterada das formas de vida dadas como possíveis. "O normal é a normatividade (instauração de novas normas) que começa com o ser vivo, e com ele advém a diversidade" (Portocarrero, 2009, p. 130).

Canguilhem identifica o nascente setor saúde como um importante dispositivo social de normalização. Ao se basear em uma perspectiva essencialmente positivista de ciência, o pensamento médico hegemônico do final do século XIX, o modelo biomédico, pautou-se pela busca de objetividade, neutralidade e universalização de suas premissas. Com isso teria abandonado seu sentido ontológico de saúde-doença, centrando-se em um saber pragmático. Nesse sentido, Ribeiro (2007, p. 49), referindo-se a esse período, comenta: "Foi por esta altura que a doença deixou de ser definida holisticamente como estado de desequilíbrio não natural, para passar a ser definida como um desvio da norma, caracterizado por um número crescente de parâmetros fisiológicos específicos e mensuráveis”.

Nesse contexto de discussão, questionar se as anomalias e as mutações são desvios da regra ou a produção de novas normas é imprescindível. De acordo com Canguilhem (2009, p. 110), a pergunta poderia ser formulada do seguinte modo: "na medida em que seres vivos se afastam do tipo específico, serão eles anormais que estão colocando em perigo a forma específica, ou serão inventores a caminho de novas formas?". O termo anomalia tem sua origem na zoologia para designar animais cujas características irregulares os fazem desviar das normas que definem as formas de vida possíveis no âmbito da história natural. São seres tomados como ponto fora da série da norma. É também um termo largamente utilizado pela anatomia patológica para descrever alterações e mudanças no organismo que se afastam, devido a sua organização imprópria e insólita, dos tipos de organização com os quais devem ser comparadas.

É nesse sentido que, para Canguilhem, o contravalor vital é a monstruosidade e a anomalia e não a morte. A morte é ameaça inexorável contra todo e qualquer sistema vivo, isto é, uma limitação exterior 
que marca o prenúncio incondicional de decomposição do organismo. "Mas a monstruosidade é a ameaça acidental e condicional de inacabamento ou de distorção na formação da forma, é a limitação pelo interior, a negação do vivente pelo não viável” (Canguilhem, 2012, p. 189). 0 monstro como o fora de lugar da norma coloca em questão a vida enquanto o modo privilegiado de nos transmitir a ordem. Dessa forma, o monstro é este outro que não é o mesmo, “outra possível norma” que não aquela esperada.

O termo mutação em biologia, por sua vez, fixa seu sentido com a genética e a bioquímica do século XX. O biólogo francês Jacques Monod (1971) afirma que a principal característica dos sistemas vivos, do ponto de vista genético e bioquímico, é que eles são altamente conservadores. Isso significa que uma das descobertas mais importantes da genética e da bioquímica do século XX foi o princípio de invariância no processo de replicação e tradução do DNA. Todavia, nem mesmo esses fenômenos microscópicos estão imunes às perturbações de ordem quântica que podem alterar a estrutura do código genético, cujo efeito, por consequência, acarretará na replicação, tradução e multiplicação do acidente singular. "Ora, uma mutação é em si um acontecimento microscópico, quântico, ao qual, em consequência, se aplica o princípio da incerteza. Acontecimento, portanto, essencialmente imprevisível por sua própria natureza" (Monod, 1971, p.131-132). Essas mutações, segundo Monod, ocorrem ao acaso e constituem a única forma de modificação do texto genético. São, portanto, as mutações genéticas a fonte de toda a novidade, de toda a criação na biosfera.

Por esta razão, Canguilhem (2005) diz que a principal conquista da biologia do século XX foi uma definição de vida desvitalizada. As anomalias e mutações não são ausência ou desvio da norma, mas funções biológicas normativas que surgem como prenúncio de novas formas de vida. Nesse sentido, é impossível fazer coincidir as anomalias e as mutações com o patológico, assim como também é impossível fazer coincidir os tipos ideais de vida com o normal.

A anomalia e a mutação não são, em si mesmas, patológicas. Elas exprimem outras normas de vida possíveis. Se essas normas forem inferiores quanto à estabilidade, à fecundidade e à variabi- lidade da vida - às normas específicas anteriores, serão chamadas patológicas. Se, eventualmente, se revelarem equivalentes - no mesmo meio - ou superiores - em outro meio - serão chamadas normais. Sua normalidade advirá de sua normatividade. 0 patológico não é a ausência de norma biológica, é uma norma diferente, mas comparativamente repelida pela vida (Canguilhem, 2009, p. 103).

Façamos o devido destaque na citação acima: as anomalias e as mutações são "outras normas de vida possíveis”, e não o desvio de predicado que confere à norma sua exceção necessária. Por outro lado, é importante lembrar também, neste momento, que todo valor só pode ser conquistado tomando como oposição um antivalor. Toda norma só terá o seu poder normativo, caso exista fora dela uma unidade não predicável que justifique, a partir de sua diferença, a consistência dos predicados, atributos e descrições positivas do regime normativo em vigor. Todo conjunto extrai sua consistência da impossibilidade de ser o conjunto de todos os elementos ou, ainda, o conjunto de todos os conjuntos. Assim, é importante lembrar que toda estratégia de normalização necessita de um quadro de referências para se fundamentar. Safatle (2015) cita como exemplo a normalização proposta no campo da saúde mental. Os transtornos e síndromes descritas nos manuais de diagnóstico como o DSM, por exemplo, são diagnosticados levando-se em consideração a frequência, intensidade e proporção de um feixe de sintomas em comparação com um quadro determinado de expectativas.

Ou seja, há um julgamento sobre proporção adequada, sobre consistência em relação a um processo de desenvolvimento psíquico pensado de maneira claramente padronizada e sobre quantidade anormal de aparecimento do fenômeno. Mas não é possível falar em proporção excessiva, em consistência com momentos no interior de um processo de desenvolvimento e em quantidade normal se o julgamento sobre a doença não pressupuser padrões claramente estabelecidos e mensuráveis de normalidade. É da desregulação quanto a tais padrões que o discurso sobre a patologia versa (Safatle, 2015, p.425-426). 
Canguilhem, vale ressaltar, não desconsidera os ganhos trazidos por essa medicina, mas destaca seus limites. Limites ainda mais importantes quando consideramos que essa ênfase pragmática, em seu tecnicismo, é condição para uma prática enquanto dispositivo social de normalização. A racionalidade biomédica, no afã positivista de que a verdade é sinônima de eficácia e de boa gestão dos riscos, reduz o entendimento sobre a saúde como ausência de doença, e a doença como afastamento da média biológica considerada normal. A saúde seria o estado normal do organismo, e a doença seu estado anormal.

Tendo este último argumento em vista, não é difícil concluir que a normalização - isto é, a institucionalização da norma como parâmetro valorativo das formas possíveis de vida - é, por assim dizer, um modo eficaz de regulação social. Toda e qualquer decisão normativa, seja ela no campo da saúde ou não, é instituidora de parâmetros, regras, modelos, padrões resolutivos dos conflitos, exercendo papel de vigilância e correção/coerção. "Portanto, a normalização aparece como tentativa de racionalização do social, como prova reguladora, axiológica e disciplinar. Ela vale por sua exterioridade, arbitrariedade e transcendência” (Moreira, 2013, p. 123).

\section{Normatividade vital: uma nova perspectiva em saúde}

Vimos na seção anterior que o estabelecimento da distinção entre o normal e o patológico, entre a saúde e a doença - não como um fato coercitivo, mas como um problema de valor individua - pode abrir um caminho fecundo para o questionamento da normatividade biológica. Na visão de Canguilhem, ao se deslocar para a zona de um dinamismo vital, o normal não é mais um conceito determinado, é a plasticidade da vida e suas infinitas possibilidades de ser vivida. O normal é a vida enquanto impossível de ter todas as suas formas predicadas já de saída. Dito de outro modo, o normal da vida é ser normativa.

Em sua abordagem filosófica sobre o conceito de saúde, de normal e patológico, Canguilhem (2009) desenvolve uma perspectiva original para o entendimento sobre as práticas de cuidado e sobre o conceito mesmo de saúde. 0 autor estabelece estudos sobre uma perspectiva ontológica da vida em suas relações com o processo saúde-doença. Assim, diferenciando-se da caracterização biomédica e pragmática da doença, centrada na efetividade do ato médico sobre a cura, Canguilhem vai colocar o processo vital como categoria central para pensar o processo saúde doença. "Assim, se Canguilhem fala em normas é para determinar o organismo, e não o meio, como potência normativa, invertendo assim a direção normalmente pressuposta da atividade normativa” (Safatle, 2015, p. 422).

Essa inversão indica, em primeiro lugar, a impossibilidade de tratarmos o meio ambiente como uma forma invariável, como campo uniforme de produção normativa. Em segundo lugar, a inversão proposta por Canguilhem nos indica outra proposta de dinamismo vital. Não são as individualidades biológicas que se adéquam ou se afastam das normas impostas pelo meio, mas ao contrário, é a individualidade biológica enquanto potência de criação de novas formas de ajustamento que produz, na sua relação com o meio, o processo de sua normatividade. A individualidade biológica produz formas singulares de ajustamento em relação ao meio: é esta potencialidade normativa de imprevisibilidade em relação ao meio, a contingência em que ela surge, que nos leva a concluir que a normatividade vital é a potência de criação de novas formas de vida. É, portanto, uma maneira de pensarmos a dinâmica da vida para além do dado, do estático e do modelo mecanizado da normalidade. Ou ainda de pensarmos o processo vital enquanto o primado do valor sobre o fato. A vida não se revela ou condiciona sua existência ao modelo pré-estabelecido das formas possíveis. Não há formas ou normas de vida em geral, "cujas formas de existência seriam assim submetidas a um princípio de ordem ou de classificação fora delas" (Macherey, 2009, p. 66).

Assim, para fazer frente ao processo de normalização - isto é, uma racionalidade que defende a naturalização e a fixidez da normalidade - Canguilhem propõe o processo de normatividade vital. A vida não cabe em normas pré-estabelecidas. Sempre as extrapola, as desvirtua, transborda todos os parâmetros. Safatle (2015, p. 336) chama atenção para "a errância própria à normatividade vital, a função da contingência na reconfiguração de formas orgânicas [...] como [...] fundamento normativo para a 
crítica social”. O biológico não inspira uma política de ordem estática, mas processual e imanente: uma política da transformação, da invenção, da tentativa. E toda tentativa contém riscos, que podem gerar, segundo as contingências das quais surgiram, perdas e ganhos para o indivíduo. Assim,

Errância implica poder se perder por completo, despender todo o processo acumulado em uma profunda irracionalidade econômica, o que explica porque a destruição do sistema é uma parte intrínseca de seu funcionamento. Pois apenas por poder perder-se por completo, ou seja, por poder deparar-se com a potência do que aparece como anormativo, que organismos são capazes de produzir formas qualitativamente novas, migrar para meios radicalmente distintos e, principalmente, viver em meios nos quais acontecimentos são possíveis, nos quais os acontecimentos não são simplesmente o impossível que destrói todo princípio possível de auto-organização. Tal figura do acontecimento demonstra como as experiências do aleatório, do acaso e da contingência são aquilo que tencionam o organismo com o risco da decomposição (Safatle, 2015, p. 357).

Ser saudável é colocar-se em risco, apostar em suas capacidades de superação, de criação, de normatividade. Pois quando a vida é "atividade de oposição à inércia e à indiferença. [...] A vida joga contra a entropia crescente" (Canguilhem, 2009, p. 107). A morte é certa, a vida que é um jogo de possibilidades para prolongar seu fim. Diferentemente da normalização ou das práticas adaptativas, "os valores mobilizados pela atividade vital não podem ser a 'utilidade', a 'função' ou mesmo o 'papel' a desempenhar. A vida ultrapassa essa contabilidade de balcão de supermercado" (Safatle, 2015, p. 337).

Seguindo essa mesma linha de raciocínio, Safatle ainda assinala que a racionalidade clínica hegemônica de nosso tempo procura, por meio da sua especialização, nos ramos da anatomia patológica, da neurociência e da fisiologia experimental, por exemplo, determinar de modo inequívoco a realidade da doença. Porém, o que esse modelo de pensamento esquece, e que não deveria de modo algum esquecer, é que essa realidade da doença só é percebida “através da consciência - veiculada primeiro pelo sujeito que sofre - de decréscimo da potência e das possibilidades de relação com o meio. Enquanto modificação global da conduta, a doença é indissociável da restrição da capacidade de ação" (Safatle, 2015, p. 427). Logo, essa racionalidade ávida por determinar a doença independentemente do sujeito doente se esquece, indiscutivelmente, da clínica!

É possível agora afirmar que a compreensão de doença que aqui defendemos não pode ser idealista ou essencialista, mas somente relacional e, por isso, acreditamos que a capacidade de ação do sujeito doente depende de seu poder de normatividade (produzir novas normas) em relação ao meio. Nada, absolutamente nada, nessa defesa nos conduz a pensar a doença como um rompimento do funcionamento normal e esperado do organismo. Mesmo funcionando de modo diferente, é possível ao sujeito, a partir de uma outra posição relacional com meio, viver a doença como uma experiência de valor positivo e não como decréscimo de potência. Segundo Le Blanc (1998), estar doente não é uma experiência marcada pela desordem, pelo transtorno ou pelo desvio da norma. Estar doente é estar próximo de uma experimentação que aumenta e alarga as leis do normal. "Por isso, podemos dizer que a doença aparece como fidelidade do organismo a uma norma única" (Safatle, 2015, p. 436). A doença é a expressão de uma forma de vida que não tolera desvio algum das condições em que ela é possível.

Contudo, não devemos acreditar que Canguilhem esteja negando a realidade da doença, ou relativizando sua natureza, pois o homem doente é aquele enodado à maquinaria da normalização, que só pode demandar ao médico sua cura, sua correção. É esse "apelo patético que faz chamar de patológicas todas as ciências que a técnica médica utiliza em socorro da vida" (Canguilhem, 2009, p. 91).

Tal racionalidade médica tornou-se hegemônica e,

levou à redução anatomofisiológica do patológico, traduzida pela desindividualização da doença, e à identificação da clínica a práticas de normalização dos processos vitais, dado o enquadramento da normalidade em critérios matemáticos e sua imposição como regra de saúde. Transposta a mesma lógica para o âmbito populacional, a desconsideração da individualidade da doença 
se acentuou ainda mais quando da extensão dos procedimentos médicos preventivos e curativos para o conjunto da sociedade, a partir das medidas higienistas, com vistas à normalização coletiva [...]. Isto é, com o higienismo e o advento da hospitalização a noção de individualidade se dissolveu no coletivo e as doenças passaram a se remeter mais à medicina que ao mal experienciado pelo paciente (Moreira, 2013, p. 172).

A medicina, longe de se fortalecer enquanto extensão da atividade vital, se transformou em dispositivo social de normalização, peça otimizadora da maquinaria de controle. Falamos da medicina, mas sabemos ser ela o paradigma inicial para outras profissões modernas de cuidado à saúde.

Portanto, não existe forma de vida que seja normal por si mesma. As normas não são a expressão direta da normalidade, mas a afirmação de uma potência de normatividade. As normas "exprimem dinamicamente um impulso que se revigora em cada vivo segundo uma orientação determinada por sua essência singular de vivo" (Macherey, 2009, p. 61). É nesse sentido que Canguilhem irá assumir uma posição epistemológica clara quando propõe abandonar as questões tradicionais relativas à normalidade em benefício da normatividade vital. As formas "normais" da vida (vivíveis e viáveis), na medida em que são formas possíveis de vida, não são "normais" pelo fato de serem apreendidas objetiva e estaticamente. Sua regularidade dever ser interpretada como a atualização dinâmica das formas de vida. Uma forma de vida normal hoje pode ser a etapa intermediária de outra forma de vida que está por vir, e não o seu caráter mais bem adaptado e acabado do ponto de vista evolutivo. $\mathrm{O}$ normal, na medida em que passa ser definido como "atualização dinâmica", não pode mais sugerir a ideia de que se serve de ponto de referência para avaliar os desvios de rota. O regime rígido da descrição e classificação dos atributos da normalidade deve ser substituído pela normatividade. Vimos com Canguilhem (2009) que a predicação positiva da norma é substituída pela normatividade enquanto o impossível de ser predicado. A dinâmica da vida é este modo em que a vida não se conforma à reprodução das formas já existentes.
Neste ponto estamos de acordo que "a noção de saúde absoluta é uma idealidade abstrata que contradiz a dinâmica própria a todos os sistemas biológicos" (Safatle, 2015, p. 423). Falar da saúde como potência normativa, isto é, afirmar que ser saudável é poder criar para si novas normas de ajustamento perante uma crise, é uma maneira de fazer da norma um processo de individualização contrário ao ideal normativo.

Ser sadio significa não apenas ser normal em uma situação determinada, mas ser, também, normativo, nessa situação e em outras situações eventuais. O que caracteriza a saúde é a possibilidade de tolerar infrações à norma habitual e de instituir normas novas em situações novas (Canguilhem, 2009, p. 148).

Nesse sentido, uma experiência de adoecimento vivenciada de maneira patológica por um indivíduo em determinado contexto pode significar, para outro indivíduo, em outro contexto, a ocasião para a produção de novas normatividades. É na doença que o organismo pode, de modo singular, encontrar a saúde. Por isso, é importante retermos que a distinção entre a saúde e a doença é incerta quando consideramos vários indivíduos simultaneamente, mas extremamente precisa quando consideramos um indivíduo sucessivamente. Segundo Safatle (2015), esse argumento ilustra o que seria uma concepção de saúde "que individualiza" e não a ratificação de uma concepção individualista e relativista da saúde.

A saúde não é um padrão que conforma individualidades a um conjunto predeterminado de regularidades a serem observadas. Padrão disciplinar que visaria, no caso humano, produzir indivíduos como entidades capazes, por exemplo, de organizar sua conduta a partir de 'regulações emotivas' e ‘processos cognitivos' socialmente normatizados. Ela é, na verdade, a capacidade de individualizar processos tendo em vista a constituição de inflexões singulares da vida. A saúde não é uma conformação, mas uma individuação geradora de processos que, do ponto de vista dos interesses da autoconservação dos indivíduos de uma espécie, podem inclusive parecer irracionais (Safatle, 2015, p. 429). 


\section{Considerações finais}

As contribuições de Canguilhem nos apresentam um conceito de saúde crítico e subversivo que tem seu fundamento desenvolvido no conceito de normatividade vital. Conforme vimos, Canguilhem contextualiza o desenvolvimento da clínica médica moderna dentro do chamado processo de normalização. Nesse contexto, a clínica é atravessada por uma perspectiva científica, de cunho positivista, que propõe métodos neutros e resultados universais, desconsiderando as singularidades imanentes em cada caso.

Se a prática clínica, atravessada pelo processo de normalização, torna-se um importante dispositivo de controle, Canguilhem não deixa de apresentar seu contrapeso: o conceito de normatividade vital. A vida é assumida em sua inescapável errância. Mais: a própria errância é apresentada como o elemento criador do novo, potencializador da vida humana.

Portanto, saúde não pode ser reduzida ao mero equilíbrio e capacidade de adaptação, uma vez que devemos considerar a saúde contendo abertura ao risco. De acordo com Caponi (2009), a definição de saúde fornecida por Canguilhem supõe uma capacidade de adaptação, porém, que a excede. "É que a explicação orgânica de ajuste ou adaptação corresponde, desde a sua perspectiva teórica, não ao conceito de saúde, mas sim ao conceito de "normalidade"” (Caponi, 2009, p. 68).

A saúde deve ser entendida como a capacidade de enfrentar as situações novas e problemáticas que interferem na vida singular de um sujeito. Desvinculando saúde e normalidade, relativiza-se o critério universalizante fornecido pelo modelo biomédico e revelam-se as singularidades dos casos. O certo é que os infortúnios, assim como as doenças, fazem parte da vida humana e, por isso, são questões que não podem ser tratadas como erros e fracassos de adaptação à norma. Ter boa saúde não implica somente ter segurança contra os riscos e infidelidades do meio. Mas também a capacidade de alteração da margem de tolerância adaptativa, ampliando assim os meios pelos quais o sujeito pode interferir na realidade transformando-a conforme seus propósitos.

Sabemos que o conceito de risco é hoje fundamental para a elaboração de estratégias e políticas de saúde pública. Robert Castel (1987) afirma que o modelo biomédico de saúde, quando utilizado como fundamento para a elaboração das estratégias de atuação no campo da saúde pública e da saúde coletiva, se caracteriza pelo deslocamento das práticas terapêuticas curativas para a administração, gerenciamento e prevenção das populações de risco. Prevenção das doenças e promoção da saúde, nesse contexto, são atitudes que significam mapear dos riscos para o exercício de uma ação vigilante quanto a emergência de acontecimentos inesperados.

Quando uma determinada população é diagnosticada como portadora de risco, a iniciativa dos gestores da saúde será a de criar hábitos saudáveis, controlando as condições sanitárias de vida e trabalho, por exemplo. Com efeito, “a prevenção é a vigilância não do indivíduo, mas de prováveis ocorrências de enfermidades, anomalias, comportamentos desviados a serem minimizados, e de comportamentos saudáveis a serem maximizados" (Rabinow, 1999, p. 141).

A consequência direta dessa orientação é considerar o risco como um obstáculo a ser evitado e superado, para que o objetivo de promoção da saúde possa alcançar o seu devido sucesso. Desse modo, dificilmente pode se elaborar, a partir da gestão do risco, a ideia de inevitabilidade e positividade de certos riscos e desafios. Seria igualmente difícil assumir que os riscos, assim como os erros e fracassos, são experiências fecundas de indeterminação, pois provocam a abertura para possibilidades de existência consideradas até então impossíveis. Spink (2007), por sua vez, corrobora com a ideia de risco como possibilidade de ganho, inerente à vida e não como algo a ser eliminado.

Com base nesses argumentos, é possível afirmar ainda que o que é mais temido na experiência do adoecimento é perceber diminuída nossa margem de segurança, isto é, nossa incapacidade de ser normativo. A tese de que a experiência do ser vivo inclui, necessariamente, a experiência da doença, indica que não existe saúde perfeita. Podemos dizer mais: é uma tese que denuncia a ilegitimidade das práticas de cura que se orientam por uma noção de saúde de pretensão generalista, e não por uma noção que individualiza o processo de restabelecimento da doença. 


\section{REFERÊNCIAS}

ASSIS. M. 0 alienista. In: COSTA, F. M. (Org.). Os melhores contos de loucura. Rio de Janeiro: Ediouro, 2007. p. 254-300.

BIRMAN, J. Mal-estar na atualidade: a psicanálise e as novas formas de subjetivação. Rio de Janeiro: Civilização Brasileira, 2001.

CANGUILHEM, G. Escritos sobre a medicina. Rio de Janeiro: Forense Universitária, 2005.

CANGUILHEM, G. O normal e o patológico. Rio de Janeiro: Forense Universitária, 2009.

CANGUILHEM, G. O conhecimento da vida. Rio de Janeiro: Forense Universitária, 2012.

CAPONI, S. A saúde como abertura ao risco. In: CZERESNIA, D.; FREITAS, C. M. (Org.). Promoção da saúde: conceitos, reflexões, tendências. 2. ed. Rio de Janeiro: Editora Fiocruz, 2009. p. 55-77.

CASTEL, R. A gestão dos riscos. Rio de janeiro: Francisco Alves, 1987.

DANTAS, J. B. Tecnificação da vida: uma discussão sobre o fenômeno da medicalização na sociedade contemporânea. Curitiba: CRV, 2014.

DUNKER, C. Crítica da razão diagnóstica em psicanálise. In: OLIVEIRA, C. (Org.). Filosofia, psicanálise e sociedade. Rio de Janeiro: Azougue Editorial, 2011. p. 281-296.

DUNKER, C. Mal-estar, sofrimento e sintoma. São Paulo: Boitempo, 2015.

FOUCAULT, M. O nascimento da clínica. Rio de Janeiro: Forense Universitária, 2008.

FRANCO, F. L. F. N. A natureza das normas: o vital e o social na filosofia de Georges Canguilhem. 2012. Dissertação (Mestrado em Filosofia) Faculdade de Letras, Filosofia e Ciências Humanas, Universidade de São Paulo, São Paulo, 2012.

LE BLANC, G. Canguilhem et les normes. Paris: PUF, 1998.

MACHEREY, P. Georges Canguilhem, um estilo de pensamento. Goiânia: Almeida \& Clement, 2009.

MONOD, J. O acaso e a necessidade. Petrópolis: Vozes, 1971.
MOREIRA, A. B. Clínica e resistência: a medicina filosófica de Georges Canguilhem. 2013. Tese (Doutorado em Filosofia) - Faculdade de Filosofia, Letras e Ciências Humanas, Universidade de São Paulo, São Paulo, 2013.

PORTOCARRERO, V. As ciências da vida: de Canguilhem a Foucault. Rio de Janeiro: Fiocruz, 2009.

RABINOW, P. Antropologia da razão. Rio de Janeiro: Relume Dumará, 1999.

RIBEIRO, J. L. P. Introdução à Psicologia da Saúde. Coimbra: Quarteto, 2007.

SAFATLE, V. O que é uma normatividade vital? Saúde e doença a partir de Georges Canguilhem. Scientiae Studia, São Paulo, v. 9, n. 1, p. 11-27, 2011.

SAFATLE, V. O circuito dos afetos: corpos políticos, desamparo, fim do indivíduo. São Paulo: Cosac Naify, 2015.

SCLIAR, M. História do conceito de saúde. Physis: Revista de Saúde Coletiva, Rio de Janeiro, v. 17, n. 1, p. 29-41, 2007.

SPINK, M. J. Sobre a promoção da saúde: tensões entre o risco na modalidade da aventura e as estratégias contemporâneas de biocontrole. In: JACÓ-VILELA, A. M.; SATO, L. (Org.) Diálogos em Psicologia Social. Porto Alegre: Evangraf, 2007. p. 387-407.

VOLICH, R. M. Psicossomática. São Paulo: Casa do Psicólogo, 2000.

\section{Contribuição dos autores}

Todos os autores contribuíram igualmente para a redação do artigo.

Recebido: I1/01/2017

Reapresentado: 22/05/2017

Aprovado: 27/07/2017 